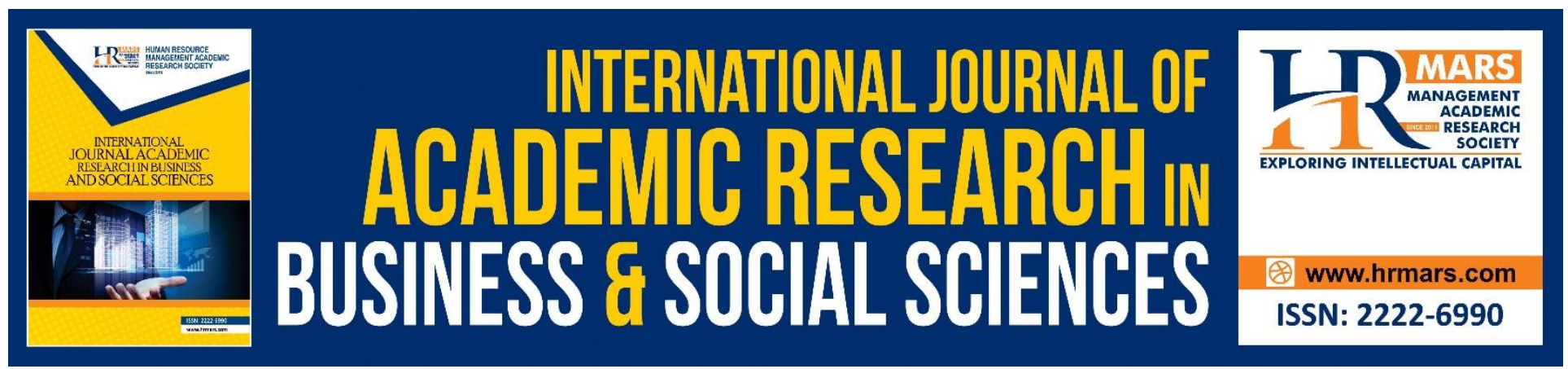

\title{
Developing a Psychometric Model for E-Hailing Jobs to Boost Malaysian B40 Income
}

\author{
Muhamad Khalil Omar, Azimah Daud. Zaimy Johana Johan, Ainie Hairianie \\ Aluwi
}

To Link this Article: http://dx.doi.org/10.6007/IJARBSS/v9-i3/5869

DOI: $10.6007 /$ IJARBSS/v9-i3/5869

Received: 01 Feb 2019, Revised: 28 Feb 2019, Accepted: 1 March 2019

Published Online: 29 March 2019

In-Text Citation: (Omar, Johan, \& Aluwi, 2019)

To Cite this Article: Omar, M. K., Johan, A. D. Z. J., \& Aluwi, A. H. (2019). Developing a Psychometric Model for EHailing Jobs to Boost Malaysian B40 Income. International Journal of Academic Research Business and Social Sciences, 9(3), 1460-1472.

Copyright: (C) 2019 The Author(s)

Published by Human Resource Management Academic Research Society (www.hrmars.com)

This article is published under the Creative Commons Attribution (CC BY 4.0) license. Anyone may reproduce, distribute, translate and create derivative works of this article (for both commercial and non-commercial purposes), subject to full attribution to the original publication and authors. The full terms of this license may be seen

at: http://creativecommons.org/licences/by/4.0/legalcode

Vol. 9, No. 3, 2019, Pg. 1460 - 1472

http://hrmars.com/index.php/pages/detail/IJARBSS

JOURNAL HOMEPAGE

Full Terms \& Conditions of access and use can be found at http://hrmars.com/index.php/pages/detail/publication-ethics 


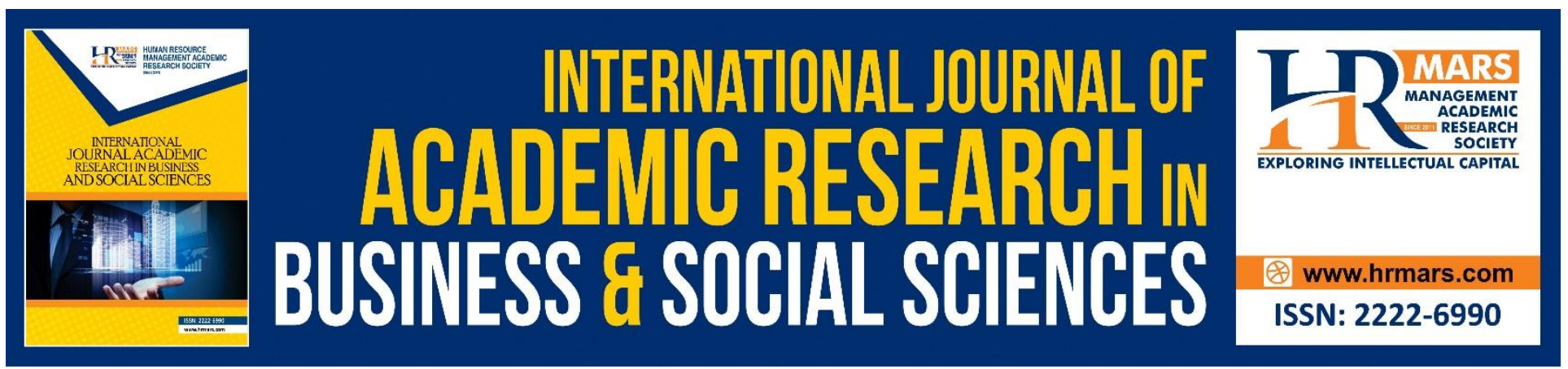

\title{
Developing a Psychometric Model for E-Hailing Jobs to Boost Malaysian B40 Income
}

\section{Muhamad Khalil Omar, Azimah Daud. Zaimy Johana Johan, Ainie Hairianie Aluwi}

Faculty of Business and Management, Universiti Teknologi MARA, Cawangan Selangor, Puncak Alam Campus, 42300 Selangor, Malaysia

\begin{abstract}
The government's incentive to encourage the low income group of B40 Malaysians to become ridesharing or e-haling drivers has given the opportunity for the group to purchase new cars with RM 4,000 rebate each. The incentive is anticipated to boost job opportunities for B40 Malaysians in becoming high-income nation by year 2020. However, till to date, the research on preferences for Malaysian citizens to opt for ridesharing job is still largely unexplored and the specification of ridesharing job is yet to be determined. Hence, this study aims to explore the factors of becoming a ridesharing driver and further develop its job specifications model. The study will employ qualitative methods of in-depth interview and focused ethnography, as well as proposing a psychometrics model for the e-haling drivers. It is expected to assist policy makers in understanding holistically the current job scenario of ridesharing drivers in order to formulate the policies, incentives and development programs. Moreover, this study will ascertain the preference and specification of ridesharing jobs in effectively attracting ridesharing workforce to enhance the B40 segment's socio-economic status. The research will also contribute to the development of sustainable transportation industry, which is one of the current national priority sectors. Similarly, by understanding the competency of e-haling drivers, effective strategies will be undertaken to ensure efficient e-haling services thus reducing private car consumption towards sustainable environment and economy.
\end{abstract}

Keywords: Ridesharing, E-Haling, Job Specifications Model, Transportation, Sustainability

\section{Introduction}

Ridesharing services is a new and growing phenomenon in Malaysia and South East Asia. Statistics shown that ride sharing services have grown into more than 60,000 drivers and 30,000 rides request per month in Malaysia (Land Public Transport Commission, 2015b) and there have been 2.5 million downloads 500,000 monthly active users and 60,000 drivers counted on ridesharing systems, with an average of three bookings per second accounted for in South East Asia (Ackaradejruangsri, 2015). 
Since its inception in Malaysia in 2012, ridesharing services has operated under the brand name of Uber and Grab. However, in March 2018, Grab has taken over Uber Southeast Asia (SEA) operations and merging the two ride-hailing giants into one. The e- hailing service has evolved from operating only in the capital city of Malaysia to other cities such as Johor Bharu, Penang, Ipoh, and recently in Kinabalu and Kuching (Land Public Transport Commission, 2015a). The rapid progress of ridesharing services has changed the operating landscape of conventional taxi services in Malaysia. This has created new interest among the Malaysia community to take part in the changing landscape. According to Lee (2016), Uber Malaysia forecasted that in 2016, there were 160,000 registered Uber drivers. In addition, 170,000 drivers were registered on GrabTaxi's mobile platforms (which run both MyTeksi and Grab Car covering all taxis, private cars, and motorcycle taxis) in Malaysia, Singapore, Thailand, Vietnam, Indonesia and the Philippines.

Nonetheless, the blooming phenomenon of ridesharing services was accused of causing market disruption and promoting the deregulation of the taxi industry (Lee, 2016). Ridesharing operators and drivers received threats for providing illegal passengers pick- up and drop off in its territory and using private drivers and vehicle. In 2016, 500 taxi drivers in Kuala Lumpur took the streets to protest against Uber and Grab, effectively shutting down major parts of the city (Lee, 2016). The objections also include safety concerns where these services do not include insurance coverage and public vehicle permit, consequently strengthen the arguments on banning ridesharing services instead. Nevertheless, the commission's proposal to transform Malaysia's taxi industry, which would include services such as Uber and Grab, was accepted by the Cabinet on August 2016 (KL to Legalise Uber, 2017).

Despite the adverse reactions from the various stakeholders, Malaysian Government in the recent Budget 2017 has announced incentives to the low income group to become ridesharing drivers. Specifically, any Malaysian citizen who qualifies for the Bantuan Rakyat 1 Malaysia (BR1M) cash aid, will be given the opportunity to buy a new car with a RM4,000 rebate for the purpose of becoming a driver for ridesharing services. This incentive is expected to generate a potential income for the low income people (B40 Segment) between RM2,000 to RM8,000 per month depending on a number of trips and passenger booking. Furthermore, the ridesharing activities shall also help to curb the environmental pollution due to the reduction of private car consumption.

While this incentive is intended to improve the socio economic status of Malaysian in the B40 Segment, but the motive of becoming a driver has not been established through research. While other studies on ridesharing services placed emphasis on service quality aspects from the users' perspectives (Teubner \& Flath, 2015; Stiglic, Agatz, Savelsbergh, \& Gradisar, 2015; Davis, 2015; Alexander \& Gonzalez, 2015), research lacks in understanding the real preference and job specification of ridesharing driver. Many researchers have also focused on taxi drivers (Zakaria, Husin \& Batau, 2010; Keong. 2015; Amirul \& Hands, 2016; Kholid, Abdullah, Ramly \& Mohamad, 2016) but neglecting ridesharing drivers. In addition, previous studies have only discussed driver issues in general without determining the attributes and specifications of ridesharing jobs. Therefore, this research aims to 
INTERNATIONAL JOURNAL OF ACADEMIC RESEARCH IN BUSINESS AND SOCIAL SCIENCES

Vol. 9, No. 3, March, 2019, E-ISSN: 222 2-6990 @ 2019 HRMARS

further enhance the understanding of these attributes thus developing them into a psychometric model and job specifications.

\section{Literature Review}

Recently, the intra-city transportation around the world received its own facelift with the advancement of technology and new business models known as 'sharing economy' (Teubner \& Flath, 2015). Internet evolution is changing the way people communicate and interact with others within their social circle (Karjalyoto, Pushel, Mazzon, \& Mauro, 2010). The growing demand for "always-on" internet connectivity is shifting usage from desktops to laptops and mobile devices. Telecommunication is also migrating not only from fixed to mobile but also from voice to data, allowing people to be connected anywhere, anytime. This leads to the advent of private chauffer services like Uber or Grab. Information system-enhanced mobility system and expansion of internet services help to improve existing fleet resources for better utilization (Teubner \& Flath, 2015). These services are known as ridesharing services; it offers benefits of a private vehicle (i.e. door-to-door services, flexibility) as well as public transportation perks (i.e. cost effective). As a result, the interest of ridesharing companies to offer applications and services via the mobile channel is increasing at the same speed as cell phone penetration.

Ridesharing Definition: Ridesharing is defined as the joint travel of two or more persons in a single car, a common way to share the cost and benefits of private cars (Teubner \& Flath, 2015; Stiglic et al., 2015). The process begins when commuters ask for a ride from a private commuter vehicle driven by a normally non- commercially licensed driver through mobile application real-time request, revitalizing the global positioning systems (GPS) and charged users based on distance fare (Davis, 2015). Much debate has gone into finding an exact meaning for this satellite-based car dispatch systems. Until the present time of this paper, there is no consensus on terminology. Other options include: "app-based rides", "on-demand rides", "ride-matching", "parataxis", "real-time ride sharing", "ride-sourcing", "ride-hailing", "e-hailing", and "Transportation Network Companies (TNCs)" (Davis, 2015; Teubner \& Flath, 2015). However, from this point further, the research will proceed with the term ridesharing to refer to these services.

In other words, ridesharing services such as Uber and Grab involve arranging for private car chauffeuring services via mobile applications, a platform that matched consumers and drivers by leveraging mobile phone GPS capabilities (Lee, 2016). Ridesharing promotes the idea of sharing the cost of traveling such as fuel and highway tolls, as well as reducing congestion and environment emissions through better utilization of vehicle capacities (Teubner \& Flath, 2015; Ma, Zheng, \& Wofson. 2013). Furthermore, ridesharing has the potential to greatly increase ride availability and city connectedness (Teubner \& Flath, 2015). Ridesharing is considered as a two-sided market; where riders benefit from more rides offered by more drivers whereas drivers can better utilize their vehicle capacity in the face of many riders (Teubner \& Flath, 2015). Studies in developing and supporting the idea of ridesharing have been carried out through the algorithm and matching calculation (Teubner \& Flath, 2015). Both types of research support ridesharing benefits in terms of fleet management as well as public transport connectivity. 
INTERNATIONAL JOURNAL OF ACADEMIC RESEARCH IN BUSINESS AND SOCIAL SCIENCES Vol. 9, No. 3, March, 2019, E-ISSN: 222 2-6990 @ 2019 HRMARS

Ridesharing or E-haling Services: Companies like Uber and Grab have launched smart phone applications that link customers with drivers in the vicinity, with GPS providing driver and customer location along with route navigation (Alexander \& Gonzalez, 2015). These services, while similar to taxis, provide a new alternative for urban travel that challenges the existing regulatory frameworks governing the taxi industry (Haider, 2015). The most prominent ridesharing service provider is Uber, originally known as Uber Cab founded in March 2009 in San Francisco. In July 2010, Uber went live for the first time in October 2010, the company decided to opt for the alternative name to Uber and it went live on Android phones in November that same year. The company has experienced a meteor increase ever since with a June 2014 valuation of \$17 Billion and a current estimate valuation of approximately $\$ 50$ Billion (Haider, 2015). The impact of ridesharing towards Southeast Asia has been enormous, affecting public transportation industry with a distinctive touch of technology-enabledplatform. This region has already prepared to engage with ridesharing, it was found that Singapore, Malaysia, Thailand, and the Philippines as the earlier adopters (Buckley \& Williams, 2014). The entrance of Uber and Grab has been explained in the attached Table1.

Ridesharing/e-haling services took over South East Asian region by storm with Grab (formerly known as MyTeksi). Grab was a result from initial idea of two Malaysian students in Harvard. To date, there have been 2.5 million downloads, 500,000 monthly active users and 60,000 drivers counted on Grab systems, with an average of three bookings per second made in South East Asia (Ackaradejruangsi, 2015). In Malaysia, the rate of adoption for ridesharing services generally has reached 30,000 active users monthly (Land Public Transport Commission, 2015a). Since its inception in Malaysia in 2014, Uber and Grab has evolved from operating only in capital city of Malaysia, these firms dispersed to other cities such as Johor Bharu, Penang, Ipoh and recently in Kota Kinabalu and Kuching (Land Public Transport Commission, 2015a). Ridesharing services has grown into more than 60,000 drivers and 30,000 rides request per month (Land Public Transport Commission, 2015b). This blooming trend somehow sparked an interest to compare ridesharing services with budget taxis in Kuala Lumpur as in Table 2. According to Uber Malaysia, it is expected that there will be 100,000 more Uber drivers in 2016 from the existing 60,000 drivers thus far. Additionally, there were more than 170,000 drivers registered on GrabTaxi's mobile platforms (which run both MyTeksi and GrabCar covering all taxis, private cars and motorcycle taxis) in Malaysia, Singapore, Thailand, Vietnam, Indonesia and the Philippines (Lee, 2016).

Table 1: Car and Motorcycle Sharing Market in Southeast Asia

\begin{tabular}{llll}
\hline Country & UBER & GRAB & Other Major Competitors \\
\hline Brunei & - & - & - \\
\hline Cambodia & - & - & - \\
\hline Indonesia & August 2014 & Jun 2015 & Go-Jek (2011), EasyTaxi (May 2013) \\
\hline Laos & - & - & - \\
\hline Malaysia & January 2014 & May 2014 & - \\
\hline Myanmar & - & - & Hoho (Myantel, Jun 2015) \\
\hline Philippines & February 2014 & May 2014 & - \\
\hline Singapore & February 2013 & July 2014 & - \\
\hline Thailand & April 2014 & April 2015 & Hailo (October 2014) \\
\hline Vietnam & August 2014 & August 2015 & May 2015 \\
\hline
\end{tabular}


Conversely, the presence of ridesharing services was accused of causing market disruption and promoting the deregulation of taxi industry. Ridesharing operators and drivers received threats for providing illegal passengers pick-up and drop-off in its territory and using private drivers and vehicle. In 2016, 500 irate taxi drivers in Kuala Lumpur took the streets to protest against Uber and Grab, effectively shutting down major parts of the city (Lee, 2016). The objections also include safety concerns where these services do not include insurance coverage and public vehicle permit, consequently strengthen the arguments on banning ridesharing services instead. Nevertheless, the commission's proposal to transform Malaysia's taxi industry which would include services such as Uber and Grab was accepted by the Cabinet on August 2016 (KL to Legalise Uber, 2017).

Attributable to extra income potential, the ridesharing jobs were advertised as to generate a cumulative earning of between RM2, 000 to RM8, 000 per month depending on number of trips and passenger request. Government of Malaysia, despite certain disputes by the traditional taxi drivers has recently promoting the potential of jobs in this alternative transportation options by granting an incentive for vehicle ownership for ridesharing jobs through announcement in Budget 2017. Specifically, any Malaysian citizen who qualifies for the Bantuan Rakyat 1 Malaysia (BR1M) cash aid, will be given the opportunity to buy a new car with an RM4,000 rebate for the express purpose of becoming a driver for ridesharing services. In an immediate response, Uber Malaysia responded that the company was delighted by the government's move in recognizing the impact of ridesharing jobs towards the socio-economic status of Malaysians in the B40 segment. Furthermore, the ridesharing activities shall also help curbing the environment pollution due to reduction of private car consumption.

Table 2: Comparison between Budget Taxi and Ridesharing Services

\begin{tabular}{llll}
\hline & Budget Taxi & Uber X & Grabcar \\
\hline Base Fare & RM 3.00 & RM 0.95 & RM 1.40 \\
\hline Per 60 Second & RM 0.40 & RM 0.25 & RM 0.24 \\
\hline Per 200 meter & RM 0.25 & RM 0.60 & RM 0.58 \\
\hline
\end{tabular}

In recent research effort, Land Public Transport Commission (SPAD) took a chance to conduct an online survey in October 2015. This is part of an extensive project with stakeholders to gather feedback, identify weaknesses and strengths to be used as data to formulate initiatives to help sustain the industry, improves drivers' welfare, and enhance services to improve customer experience. The survey showed more than eighty percent of forty-six thousand respondents have the experience using ridesharing services like Uber and Grab (Land Public Transport Commission, 2015b). The motivation for users to switch for ridesharing services are mainly contributed by reliability and affordability factors. Incidentally, the survey only discussed the issue without properly determining the realistic attributes and overall specification of ridesharing jobs which should be addressed in understanding the motives in preferring such job as well as its relevant human requirements to effectively employing it. 
However, till to date, the preferences for Malaysian citizens to opt for the ridesharing jobs as a driver were still in the shadow as no study is conducted on this phenomenon. Past researches shows tendency to focus on the aspects of ridesharing provisions. Studies of algorithm matching and path calculation (Teubner \& Flath, 2015), safety aspects of ridesharing services (Davis, 2015), and formulating a matching platform for ride request (Bicocchi \& Mamei, 2014) has been explored empirically. Locally, taxi services related literatures provide very limited sources as most researches focuses on drivers' intention to adopt mobile apps (Keong, 2015), review on Malaysian taxi scenario (Amirul \& Hands, 2016), taxi drivers' attitude towards passengers (Kholid et al., 2016), job characteristics of taxi drivers and service quality of taxi services (Zakaria et al., 2010). This warrants for further investigation through this study that aims to explore the motives of becoming a ridesharing driver and further develop a specification model for this job.

Job Preference Model: However, past studies in the area of ridesharing are still underdeveloped in terms understanding the overall reasons or motives for a person to become a ridesharing driver. A study among 257 undergraduates in England by Wiswall and Zafar (2016) found that income, type of work, rewards, hour of work, security, flexibility and personal profiles were the factors in determining job preferences. Another study by Grund (2011) among 2,861 workers of various jobs in Netherland established that regulation, workload, commuting time, image, environment, autonomy, prestige, benefits, advancement opportunity, challenging work, location, and dress code would be other considerations in choosing a job. Recently a study by Buckley and Williams (2014) had introduced Facet5 concept in identifying work preferences according to a person's will, energy, affection, control, and emotionality. On top of that, by inferring to the expectancy theory (Vroom, 1966) which states that individual (job) choice decisions depend on "subjectively determined importance weight by the subjectively assessed degree to which the job offers that particular attribute. A job preference model is proposed as per Figure 1 as attached.
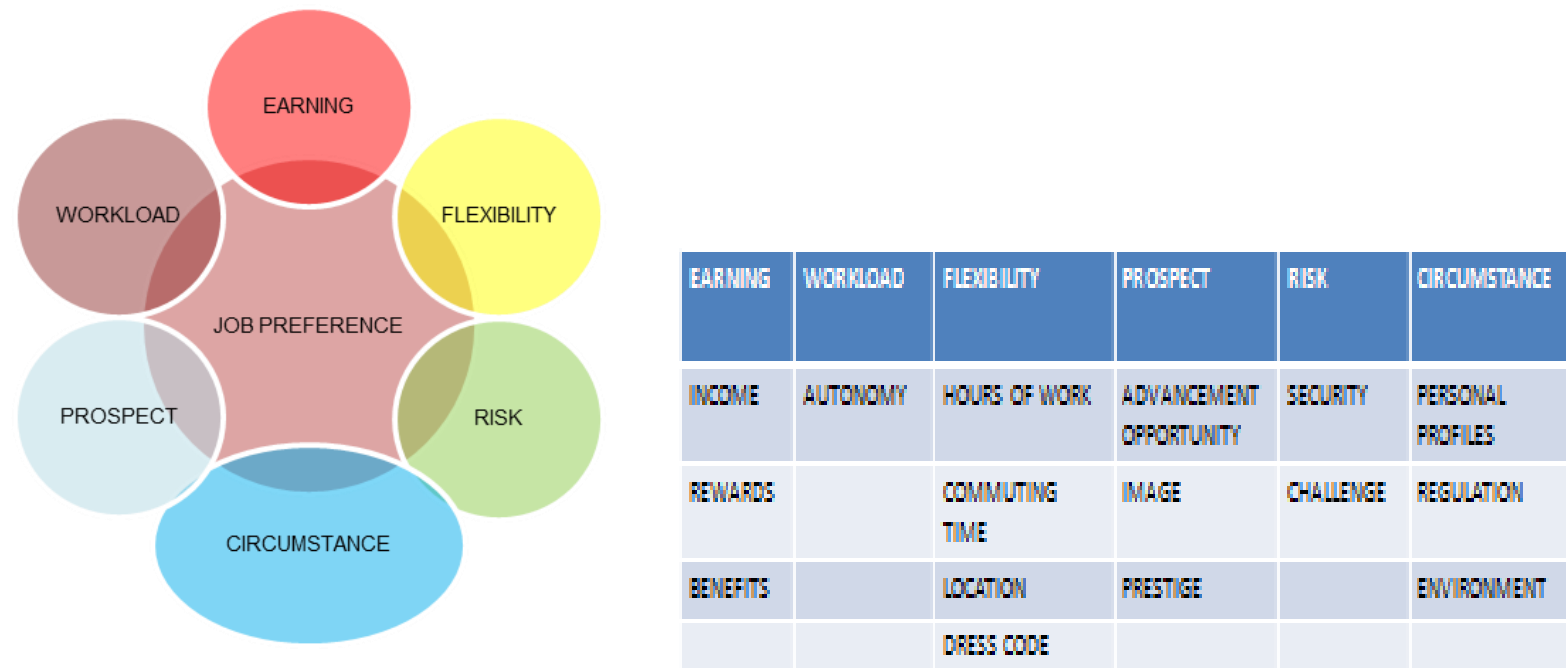

Fig. 1: Proposed Job Preference Model 
Job Specifications Model: Similarly, there are scarce studies that investigate the elements of job specification or human requirements for a ridesharing job. Job specification, also known as employee specifications, includes a definition of qualification, personality and other characteristics, traits or personal attributes (or competencies i.e. knowledge, skills, and abilities), that the employee must meet or has in the particular job (Sackett \& Laczo, 2003). Job specification is important as it is helpful in preliminary screening in the selection procedure, giving due justification to each job, designing training and development programs, counseling and monitoring performance of employees, evaluating job and appraising performance as well as guiding the management to take decisions regarding promotion, transfers and giving extra benefits and rewards to the employees (Pató, 2015). Basing on psychometrics theory and technique that concerned with the objective measurement of skills and knowledge, abilities, attitudes, personality traits, and educational achievement (Michell, 1999), a job specification model is proposed as per Figure 2 as attached.

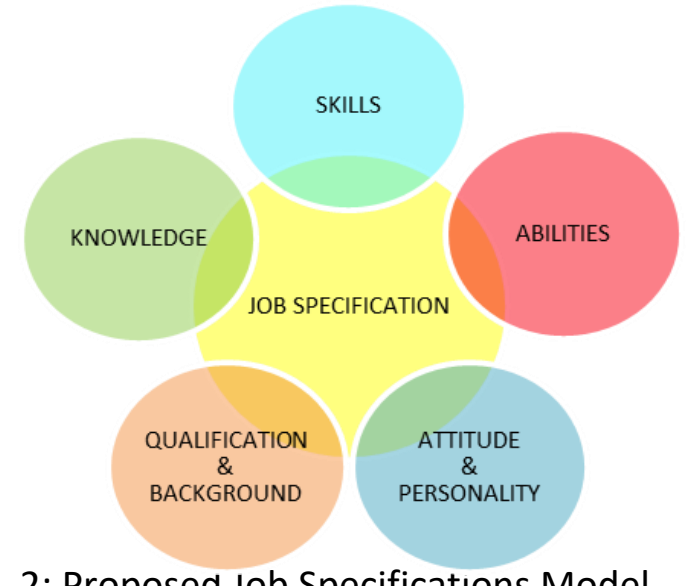

Fig. 2: Proposed Job Specificatıons Model

\section{Research Methodology}

The purpose of this study was twofold. First, is to explore key motives or rationales for preferring a ridesharing job as a driver. Second, is to ascertain the applicable human specification in becoming a ridesharing driver. 
Research Design: This study's research design involved the utilization of qualitative research methods in addressing the research questions. This is because qualitative research offers the greatest promise of making significant contributions to the knowledge base and practice because it is focused on discovery, insight, and understanding from the perspective of those being studied. A qualitative approach was considered more relevant to undertake this research as it will allow greater capacities to gain more depth and meaning based on an individual's experiences of ridesharing jobs. Specifically, research strategy of focused ethnography shall be applied in this study since this method is short-term and flexible thus applicable for diverse and short-term fields activities. Ethnography can also uncover the tacit skills, complexities, and discretion in jobs that may be routine or marginal and reveal how power, control, and inequality are sustained in many work environments (Smith, 2001). This ethno methodologically indirectly applying a constructivist approach within this qualitative method of inquiry that allows for the study of the "how-and sometimes why- participants construct meanings and actions in specific situations" (Charmaz, 2006).

Population, Sampling and Respondents: The population of this study is all ridesharing drivers in Malaysia and the numbers are currently unknown, but based on unofficial information from the internet, the total numbers are approximately 200,000. Unit of analysis is individual for profit ridesharing drivers currently registered with ridesharing operators of Grab Malaysia. Purposive sampling technique will be employed and a quota of 100 drivers is targeted to be approached based on their location, which are, Klang Valley (40\%), Ipoh (10\%), Penang (15\%), Johor Bahru (10\%), Kuching $(10 \%)$, and Kota Kinabalu(10\%). By relying on social networking among existing drivers, a snowballing method will be adopted to ensure a pool of informed and interested interviewees and at the same time minimize the potential interviews be over-represented by certain groups of drivers at the expense of others. This study will utilize in-depth, face-to-face semi-structured interviews as the primary method of qualitative data collection.

Data Collection Method: At the beginning of this study, official permission to conduct study shall be requested from Grab ridesharing operators in Malaysia. A preliminary interview with the personnel incharge of sourcing for ridesharing drivers will also be executed to identify the validity of the semistructured interview questions that will be used for the actual data collection. Their expert opinion and experience with regards to motives and rationale behind the preference for ridesharing jobs as well as the relevant specification required for the job. Applicable printed and online documents from both ridesharing operators shall also be analyzed such as legislation, procedures, application forms, sourcing practice standards, and guidelines for ridesharing service, driver statements, and operators' websites. Upon approval of the permission request, a pilot interview would be performed with a minimum10 ridesharing drivers to identify any required improvement on the questions and procedures. For this study, actual data collection, interviews and participant observation (through ride-along as a passenger and the use of the apps for e-hailing) will be used to get a sense of the range of motivations and person specification required by for-profit ridesharing drivers as they make use of the service. Informed consent for the interview and audio-taping will be obtained before the commencement of the interview and tape recording. Interviews will be varied in length between $40-$ 60 minutes. 
As is standard in qualitative research, data analysis is an ongoing, recursive process of reading, discussing and reflecting on the data as it is collected. Therefore, after the interviews were transcribed, the research team will meet to discuss initial themes for the data. The qualitative data will go through narrative analysis using ATLAS.ti software following processes of data reduction, data display, and conclusion drawing and verification. Data reduction involves the procedures of selecting, coding, simplifying, extracting, and categorizing written field notes, transcripts, and other available resources in order to identify persistent words, phrases, and ideas that could be ultimately grouped into themes and patterns. Data display is used to incorporate information into an accessible summary to facilitate later conclusion drawing which relies on psychometrics concept and technique including procedures of data abstraction, comparison, dimensionalization and integration. Conclusion drawing and verification will be executed to verify the findings that are appropriate before they are labeled as conclusive results. It is expected that upon completion of all possible domains, the research team can come to a consensus on the outcome of final core idea and category that could be described, explained, or interpreted as the conclusive models for preference and specification of ridesharing job as a driver.

\section{Discussion and Conclusion}

Ridesharing services are still new and growing phenomenon in Malaysia and South East Asia, and with government's incentive to the B40 group of Malaysians is timely to achieve its target of becoming high income nation by year 2020. By proposing psychometric and job specifications models, the research outcomes are expected to support relevant government agencies in strengthening the policies, regulations, directions and incentives for ridesharing services in developing a sustainable and efficient transportation system in Malaysia. The significance of study are exploring the models for preference and specification of ridesharing jobs to effectively attracting ridesharing workforce in enhancing the B40 segment's socio-economic status, assisting the policy makers to understand the applicable competencies of e-haling drivers, thus enabling effective policies, incentives and screening strategies to ensure efficient e-hailing services and reducing private car consumption towards the development of sustainable transportation industry and environment.

\section{Acknowledgement}

This research is funded by the Bestari Research Grant Scheme (600-IRMI/DANA 5/3/BESTARI (P) (031/2018) from Universiti Teknologi MARA, Shah Alam, Malaysia.

\section{References}

Ackaradejruangsri, P. (2015). Insights on GrabTaxi: An Alternative Ride Service in Thailand. Review of Integrative Business and Economics Research, 4(3), 49-61.

Alexander, L., \& Gonzalez, M. (2015). Assessing the Impact of Real-time Ridesharing on Urban Traffic using Mobile Phone Data. Presented at the UrbComp '15, Sydney, Australia.

Amirul, F. R., \& Hands, D. (2016). The Taxi Service Review: Malaysia Context. Mediterranean Journal of Social Sciences, 7(4), 559.

Bicocchi, N., \& Mamei, M. (2014). Investigating ride sharing opportunities through mobility data analysis. Pervasive and Mobile Computing, 14, 83- 94. 
INTERNATIONAL JOURNAL OF ACADEMIC RESEARCH IN BUSINESS AND SOCIAL SCIENCES

Vol. 9, No. 3, March, 2019, E-ISSN: 222 2-6990 @ 2019 HRMARS

Charmaz, K. (2006). Constructing Grounded Theory: A Practical Guide Through Qualitative Analysis. London: Sage.

Davis, J. (2015). Drive at Your Own Risk: Uber Violates Unfair Competition Laws by Misleading Uberx Drivers about Their Insurance Coverage. Boston College Law Review, 56(3), 1097-1142.

Grund, C. (2011). Job Preferences as Revealed by Employee Initiated Job Changes. (IZA Discussion Paper No. 6127). Bonn, Germany: The Institute for the Study of Labor.

Haider, M. (2015). To Uber or Not to Uber: That is the Question. Unpublished manuscript.

Karjaluoto, H., Püschel, J., Mazzon, J. A., \& Mauro C. Hernandez, J. (2010). Mobile banking: Proposition of an integrated adoption intention framework. International Journal of Bank Marketing, 28(5), 389-409.

Keong, W. E. Y. (2015). Factors Influencing Malaysian Taxi Drivers Behavioral Intention to adopt Mobile Taxi Application. International Journal of Economics, Commerce and Management, 3(11), 1-150.

Kholid, F. N., Abdullah, S., Ramly, K., \& Mohamad, S. J. A. N. S. (2016). Improving the Taxi Drivers' Attitudes in Discharging Better Services to the Passengers in Klang Valley, Malaysia. International Journal of Scientific Research, 4(8).

Lee, P. (2016, January 4). 100,000 More Uber Drivers. The Star. Retrieved from http://www. thestar.com.my

Ma, S., Zheng, Y., \& Wolfson, O. (2013). T-Share: A Large-Scale Dynamic Taxi Ridesharing Service. Data Engineering (ICDE), Presented at 2013 IIEEE 29th International Conference, 410 - 421.

Michell, J. (1999). Measurement in Psychology. Cambridge: Cambridge University Press. DOI: 10.1017/CBO9780511490040

Pató, B. S. G. (2015). The 3D job description. The Journal of Management Development, 34(4), 420406.

Sackett, P. R., \& Laczo, R. M. (2003). Job and Work Analysis: Industrial and Organizational Psychology. In W. C. Borman, D. R. Ilgen, \& R. J. Klimoski (Eds.), Comprehensive Handbook of Psychology, Volume 12: Industrial and Organizational Psychology (Vol. 12). New York, NY: John Wiley and Sons.

Stiglic, M., Agatz, N., Savelsbergh, M., \& Gradisar, M. (2015). The benefits of meeting points in ridesharing systems. Transportation Research Part B: Methodological, 82, 36-53.

Land Public Transport Commission (2015a). Customer Satisfaction Survey Report 2015. Retrieved from www.spad.gov.my/report

Land Public Transport Commission (2015b). General Perception Taxi Service in Malaysia. Retrieved from www.spad.gov.my/report

Smith, V. (2001). Ethnographies of work and the work of ethnographers. In Paul Atkinson, Amanda Coffey, Sara Delamont, John Lofland \& Lyn Lofland (Eds.), Handbook of ethnography (pp.220233). Thousand Oaks, CA: Sage.

Teubner, T., \& Flath, C. M. (2015). The economics of multi-hop ride sharing. Business \& Information Systems Engineering, 57(5), 311-324.

Vroom, V. H. (1966). Organizational choice: A study of pre- and post-decision processes. Organizational Behavior and Human Decision Processes, 1, 212- 225. 
INTERNATIONAL JOURNAL OF ACADEMIC RESEARCH IN BUSINESS AND SOCIAL SCIENCES

Vol. 9, No. 3, March, 2019, E-ISSN: 222 2-6990 @ 2019 HRMARS

Wiswall, M., \& Zafar, B. (2016). Preference for The Workplace, Human Capital, And Gender. (NBER Working Paper No. 22173). Cambridge, MA: National Bureau of Economic Research.

Zakaria, Z., Husin, Z., \& Batau, M. F. A. (2010). Service Quality of Malaysian Public Tranports: A Case Study in Malaysia. Cross-Cultural Communication, 6(2), 84-92. 